\title{
Communication Skills among the Final Year Engineering Students in an Autonomous Engineering College in Coimbatore, India: an Evaluation
}

\author{
K.Srigayathridevi \\ R. Thamaraiselvi
}

\begin{abstract}
A survey was conducted to assess the overall communication skills of final year Engineering students of Engineering College in Coimbatore. Sample sizes of 145 students were selected from nine different branches of engineering courses. The survey was conducted through a 5 point scale questionnaire. Three main factors of communication skills like speaking, writing and listening were considered to assess the respondents. They were found to be fairly good in speaking and writing and poor in listening.
\end{abstract}

Key words: communication skills, engineering students

COMMUNICATION IS THE INTEGRAL part of any individual. It is also the foundation for sharing information. We spend more time in communicating than doing anything else: talking, listening and interacting with others. Irrespective of caste, creed, gender and age, communication is essential to our personal, professional and civic lives.

The need for effective communication tends to be increasing due to globalization, science, technology and trade. Because of enormous competency in the digital society, it is essential for the next generation to be well equipped with the basic skills of communication. Engineering students require communication skills to enhance their technological knowledge and thereby excel in their career. Technology and communication should go hand in hand. So, a study was carried out to find out whether the engineering students are able to communicate effectively to their satisfaction.

\section{Objectives}

1. To evaluate the overall communication skills among the Engineering students.

2. To assess and compare the effectiveness in speaking, writing and listening among the various branches of engineering students.

\section{Methodology}

A predetermined structured questionnaire with a set of 32 questions pertaining to the area of speaking skills, written skills, presentation skills, feedback, nonverbal communication and listening skills was used to collect the data. A 5 point scale (always, frequently, sometimes, rarely, never) was adopted. For the positive questions the scoring pattern was 5, 4, 3, 2, 1 and for the negative questions it was vice versa.

The population was defined in terms of the total number of engineering students of 9 different branches. The total number of population defined in this term was 400 . Out of this, 145 students were sampled using the stratified judgmental sampling technique. The target sample was clearly focused as and to get an over all result in each branch. The samples were taken from three levels: top, average and below average students. 


\section{Communication Skills among the Final Year Engineering Students...}

3. Analysis

1. Overall, the speaking skills of the students are found to be good. Among the nine batches, the Sandwich (Mechanical) and Production students seem to use appropriate language and speak fluently, but do not respond immediately to questions (Appendix 2\& 3).

2. Mechanical and ECE students feel that they are able to identify the potential barriers in communication to a great extent but they feel uncomfortable while interacting with strangers (Appendix 4).

3. Computer science and Metallurgy students can capture their audiences' attention very well but they have responded that they are at loss for words while communicating with others.

4. Metallurgy students believe that they are satisfied with their writing skills. However, while writing, they are unable to respond effectively

5. Sandwich (Mechanical), Sandwich (ECE) and EEE students feel that they are able to write complete and coherent messages, even though they are not good at planning the messages. (Appendix 5 \& 6).

6. Though Sandwich (Mech) students revise the message before passing, they feel that their messages are not clear and concise. On the other hand, Production and Sandwich (EEE) are able to produce clear and concise messages, in spite of revising the message before passing.

7. Sandwich (Mech) and Metallurgy respondents feel that their mind wanders when people talk to them however; they listen well to complex information (Appendix 7).

\section{FINDINGS/RESULT}

Based on the above analysis on engineering students regarding their communication skills, the following were found:

1. Sandwich (Mech) students have good fluency and usage of appropriate language. They are unable to understand the barriers to communication and hence they feel more uncomfortable while talking to strangers. They lack in planning the written messages before passing it. Therefore their messages are not clear and concise. Also they fail to revise the message properly. They seem to lack in concentration while listening and hence they get confused and do not understand messages.

2. Production students are using appropriate language and are fluent in communication. But they do not respond immediately. These students are poor listeners. So they feel bored when they listen continuously.

3. The sandwich EEE students were found to be poor in planning and revising their messages.

4. Computer science students are able to capture the audience attention, but they feel they are at loss for words while communicating.

5. Students of $E E E$ batch seem to be lacking in planning the messages.

6. The ECE students are good in understanding the barriers to communication and yet feel uncomfortable while communicating with unknown persons.

7. The students of Metallurgy are able to hold the audience well, but feel at loss for words due to their low level of fluency and inappropriate language.

8. Mechanical students tend to respond immediately but they feel uncomfortable while interacting with strangers. 


\section{The Journal of Nepalese Business Studies}

All the nine batches of engineering students seem to be poor listeners. This may be due to lack of interest, uninteresting speakers, uninteresting topics, physical and semantic barriers, lack of concentration and lack of knowledge in subject matter.

9. Analyzing the overall communication skills, it has been found out that, metallurgy students are poor; IT, Sandwich Mechanical and Production students are in the average level, sandwich EEE and ECE students are better and computer science and Mechanical students are excellent in their communication skills.

\section{Suggestions}

1. Batch 1 (Sandwich Mech) students should be aware of the potential barriers to communication and improve their interpersonal communication. They have to plan and revise well before passing any written message, so that the messages are clear and concise. They have to develop concentration to improve listening skills.

2. Batch 2 (Production) students can still improve their fluency and enrich their knowledge; they should also revise the messages so as to make their written communication effective. They should improve their listening skills and try to create an interest.

3. Batch 3 (Sandwich EEE) students can make their communications more effective when they put in more efforts in reading and writing.

4. $\quad$ Batch 4 (IT) students may be technically sound in their subject but seem to be weak in all forms of communication. They can take up a training programme to change their style in speaking and writing messages.

5. Batch 5 (Computer Science) students should enrich their vocabulary to be confident in speaking.

6. Batch 6 (EEE) students have good language and fluency, if they can plan their messages their communication could be excellent.

7. Batch 7 (ECE) students can improve their interpersonal skills to overcome the barriers and feel comfortable while talking to strangers.

8. Batch 8 (Metallurgy) students should spend more time in reading and acquiring information by all means to excel in their communication.

9. Batch 9 (Mechanical) students are able to identify the barriers to communication and hence they can easily develop interactive communication skills.

\section{Conclusion}

In the digital revolution, students are expected to possess communication skills so as to prove their abilities in their career. Hence research was undertaken to develop criteria to measure effectiveness of speaking, writing and listening skills among the engineering students.

It has been identified that among the nine batches of engineering students only few batches are found to be excellent communicators. The other batches seem to have the basic communication skills; however they need to take initiative to improve themselves. Some suggestions are furnished to these students in each area of communication to enhance their performance.

The overall communication audit of Computer Science and Mechanical students were found to be excellent, whereas sandwich (EEE), EEE and ECE are good and can still try to excel. However, Production, Information Technology and Sandwich (Mechanical) students are average performers. So they should ensure to develop their speaking, writing and listening skills. The Metallurgy students seem to be very poor communicators. These students must realize that communication skills are powerful strategic weapon used to inculcate good skills in them. 
Based on the outcome of this research, the institution can encourage the batches that are excelling in communication and give opportunities for the batches that are poor in communication to improve by means of training cum skill development programs.

\section{Appendix 1}

Fig 1: Batch Profile

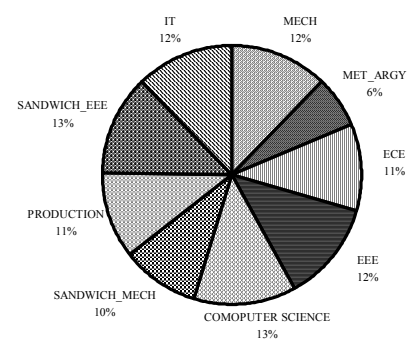

Fig. 2: I Respond to Questions Immediately

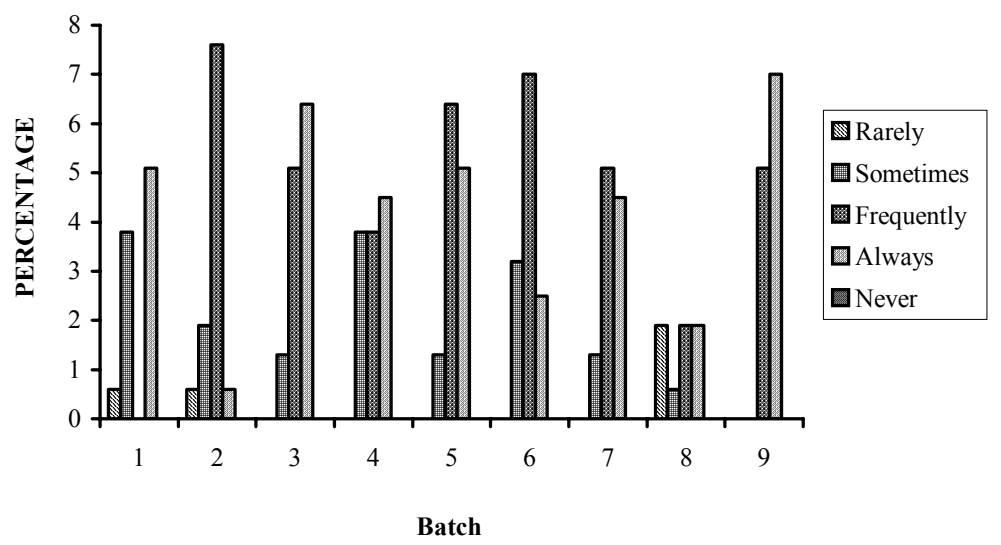


Fig.: 3: I Can Speak Fluently

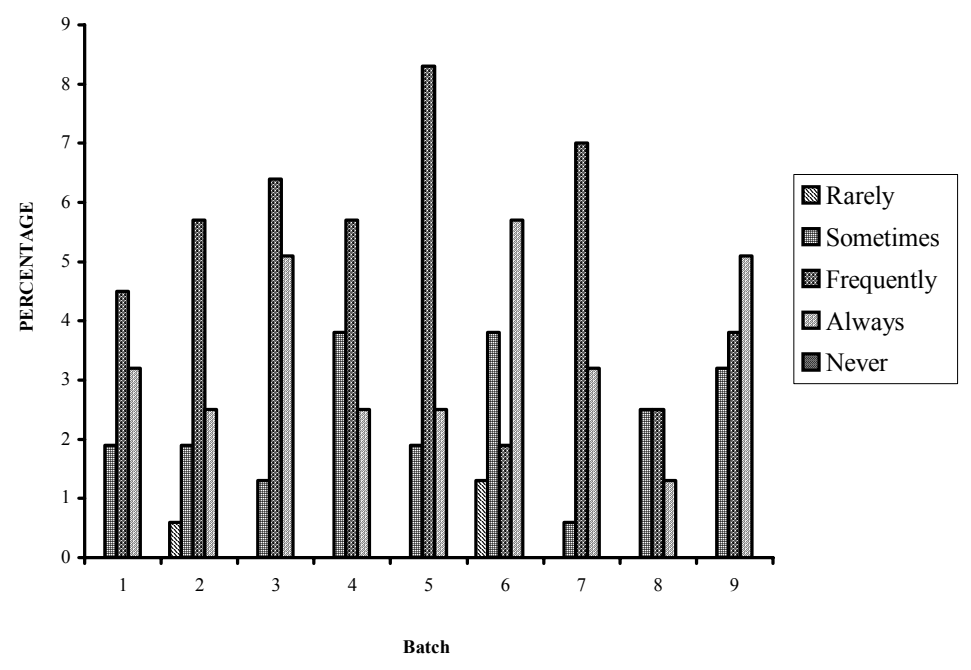

Fig. 4: I Understand the Potential Barriors to Effective Communication

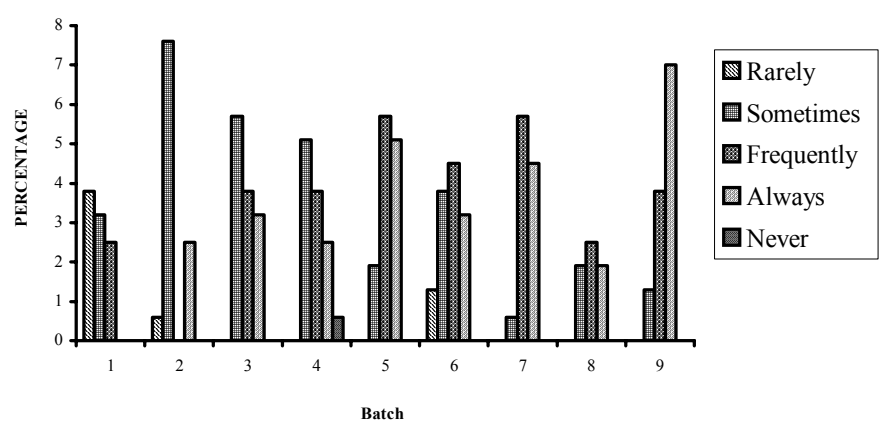

Fig. 5: I Know How to Make My Messages Coherent and Complete

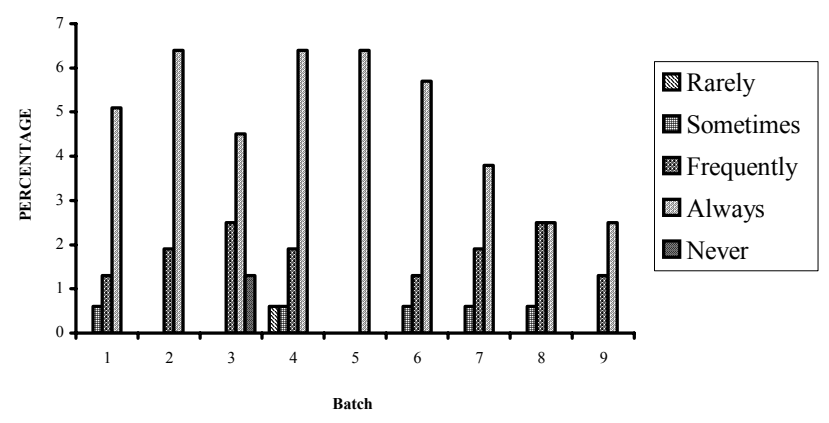


Fig. 6: I Plan What I AM Going to Write Before I Start
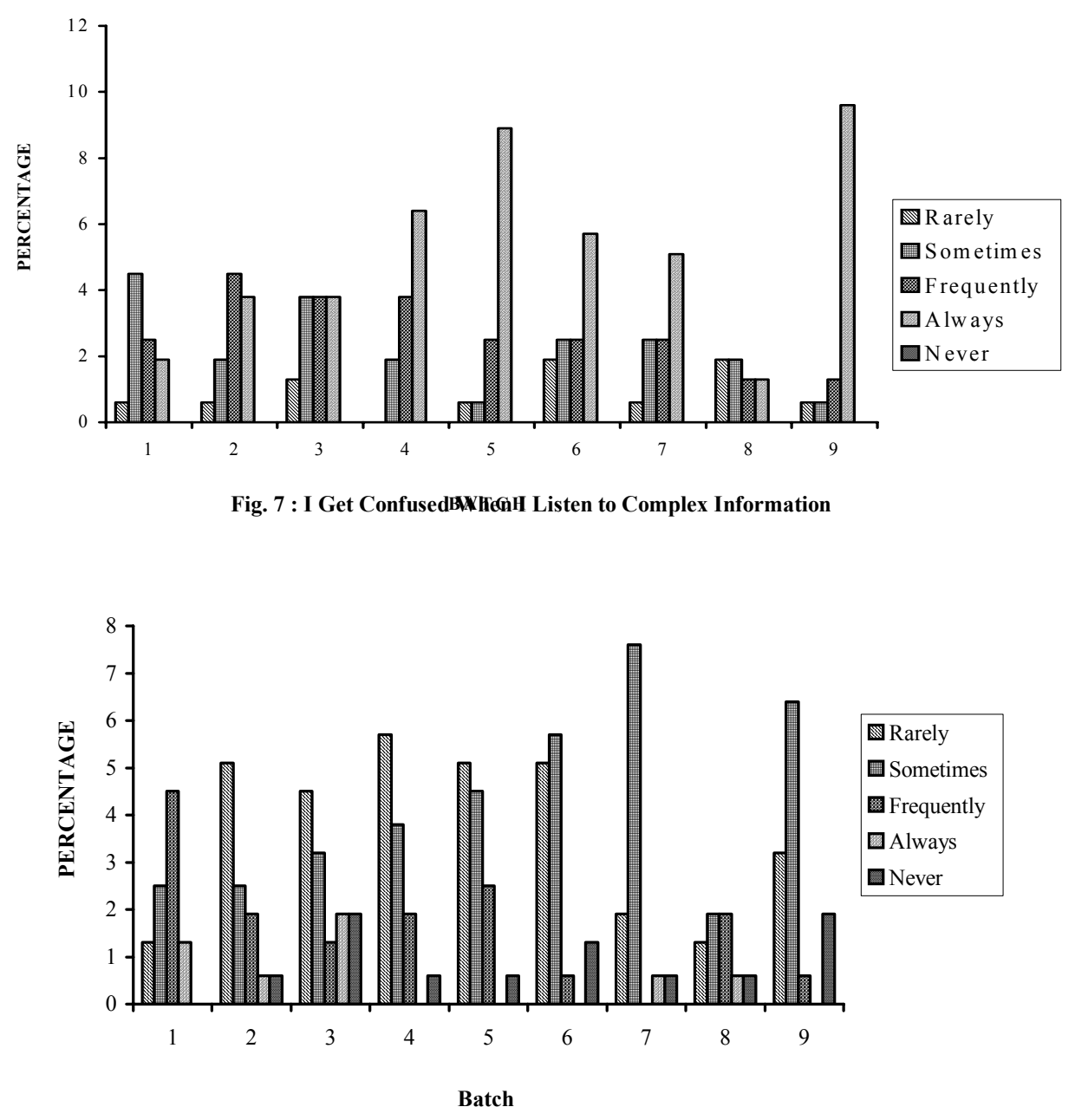

\section{REFERENCES}

Kothari, C.R. Research Methodology, Methods \& Techniques. $2^{\text {nd }}$ ed. Wiley Eastern Ltd. Fruehling, T. \& Joan M. Lacombe. Communicating for Results. A.I.T.B.S. Publishers \& Distributors.

Hurst, Bernice. The Handbook of Communication Skills. $2^{\text {nd }}$ ed. Kogan Page Ltd. 